of living things, or that department which deals with the mode of life of organisms-habits, relation to the environment, \&c. ; the former use of the term is almost universal in Englishspeaking countries, but many of the leading German writers give it the other signification. Again, morphology and anatomy are terms of fundamental importance, and zoologists and botanists might surely agree upon a common definition for each. The same applies to other terms common to the two sub-sciences, ovary being the most flagrant example of divergence. To take one more example, the word biogenesis was introduced by Prof. Huxley to signify the origin of organisms from pre-existing organisms. Eimer, in his recent work on organic evolution, uses the term biogenetic law for the law that individual recapitulates ancestral development.

Another matter, which might certainly be settled once for all, is the meaning to be attached to adjectives and prefixes denoting position, such as dorsal and ventral, anterior and posterior, proximal and distal, mesial and lateral, epi-, hypo-, pre-, post-, \&c. Such terms of position, although easy enough to apply in most cases, are constantly being misused ; epipubis (for pre-pubis) is a modern and widely-used term; the dorsal and ventral roots of the spinal nerves are still frequently called anterior and posterior, and the great body-veins the superior and inferior venæ cavæ; and the botanical use of many terms of position (e.g. the dorsal and ventral sutures of a carpel) is absolutely mean. ingless.

Another step in the right direction would be the publication, under the auspices of the British, American, and Australasian Associations, the Anatomische Gesellschaft, and similar bodies, of a glossary of biological terms, in which the history of the word, its inventor, the precise sense in which he used it, and any subsequent changes of meaning it may have undergone, would be set forth. Such a glossary might, I think, be usefully arranged under somewhat similar headings to those employed in the Zoologischer Fahresbericht, the whole work being of course supplied with an alphabetical index. With a single responsible editor, and a sub-editor for each department, the work would not be one of insuperable difficulty.

An even more practicable suggestion than the last, and one which, although supplementary to, is not dependent upon it, is that in such publications as the Zoological Record, the Journal of the Royal Microscopical Society, and the Zoologischer Fahresbericht, there should be a record of new terms as well as of new species. The recorders who do the work of these publications with such fidelity and success, would hardly find their labours increased by noting down all the new terms used by the authors in their various departments, and placing them in a special list, each being accompanied by name of author, date, and definition. If this were done, we should have fewer instances both of useless synonyms and of identical words being employed for totally distinct things. I do not think, for instance, that the body-cavity of Peripatus would have been called a pseudocale by Mr. Sedgwick, or a metacale by $\mathrm{Mr}$. Hatchett Jackson, if these writers had had the means of knowing that the former term had been previously applied by Dr. Burt Wilder to the so-called fifth ventricle of the mammalian brain, and the latter to the fourth ventricle.

Finally, matters would be very much improved if every author who finds himself obliged to coin a word would notify the fact in a conspicuous part of his paper, accompanying the term with an adequate definition. One has only to point to Allman's monograph on the Gymnoblastic Hydroids, or to Haeckel's Report on the Deep-Sea Medusæ, to give a practical instance of the advantage of such a practice.

My proposals for promoting greater uniformity of nomenclature in biology may therefore be summed up under three heads, as follows :-

I. The appointment of a strong international committee to define terms of general and fundamental importance, such as the subdivisions of biological science, terms cornmon to zoology and botany, terms denoting position, \&c.

2. The issue of an authoritative historic al glossary.

3. The systematic record of new terms,

\section{METEORIC IRON}

THE Annalen des k.k. naturh. Hofmuseums, No. 2 of vol. vi., contains a further contribution by $\mathrm{E}$. Cohen and $\mathrm{E}$. Weinschenk to their interesting studies on meteoric irons.

By treating comparatively large masses in the cold with very dilute hydrochloric acid ( $\mathrm{I}$ in 20 ) so that the process of solution was very slow, in some cases extending to several months, a residue is left from which it is found possible to isolate several more or less definite compounds, distinct from the freely soluble main mass of the meteorite.

It is in the portion insoluble in the highly dilute acid, which in some cases amounts to no more than 5 per cent. of the whole, that the main interest in analytical work on meteoric irons centres. The patience and care involved in the separation of its various constituents often find their reward in some interesting discovery. As a typical example of the constituerits into which a meteorite may be separated by this treatment with dilute acid, it will suffice to quote the percentage numbers obtained in the case of a slice of the Magura iron. They are as follows:-

Nickel-iron which passed into solution 92.67 per cent.

\begin{tabular}{|c|c|c|c|c|}
\hline henite & & & & 4.00 \\
\hline Tænite + jagged fra & nents & $\cdots$ & $\ldots$ & 0.13 \\
\hline Schreibersite & $\ldots$ & $\ldots$ & $\cdots$ & 0.09 \\
\hline Tænite + cohenite & $\ldots$ & $\ldots$ & $\cdots$ & 2.93 \\
\hline Non-magnetic residue & & $\ldots$ & $\ldots$ & 0.18 \\
\hline
\end{tabular}

In most meteoric irons the soluble portion consists to a large extent of a nickel-iron kamacite, which mainly constitutes the broad layers of the Widmanstätten figures seen on an etched polished surface. The authors are of opinion, from a comparison of various analyses, that this alloy has a constant composition represented by the formula $\mathrm{Fe}_{14} \mathrm{Ni}$.

Cohenite, which occurs in very brittle tin-white crystals, has at present been only found in the Magura iron. It was analyzed and described in a previous paper by Dr. Weinschenk, who found it to consist of a definite carbide of iron, nickel, and cobalt, having the composition represented by the formula $(\mathrm{FeNiCo})_{3} \mathrm{C}$. Very similar crystals in the Wichita iron were found to have the composition represented by the formula $(\mathrm{FeNiCo})_{4} \mathrm{C}$, analogous to the well-known spiegeleisen, $\mathrm{Fe}_{4} \mathrm{C}$. Cohenite corresponds to the carbide $\mathrm{Fe}_{3} \mathrm{C}$, which separates out in crystals when cast-iron is slowly cooled between $600^{\circ}$ and $700^{\circ}$. Many points of resemblance such as this between meteoric and ordinary cast-iron appear to show that the conditions as regards temperature, \&c., during their production must have been very similar in the two cases.

Tænite, occurring usually in thin silver-white lamellæ of great toughness between the broader layers of kamacite, is a nickel-iron, of which there appear to be two varieties, containing respectively about 65 and 73 per cent. of iron. Further analyses, however, are necessary in order to determine its true composition. The jagged and angular fragments of iron-black colour were analyzed, and found to consist of a nickel-iron containing about 7 per cent. of -nickel, and were thus in all probability identical with kamacite.

The phosphor-nickel-iron schreibersite is generally found in large tabular crystals of tin-white colour. The new analyses show that its composition may be represented by the formula $(\mathrm{FeNiCo})_{3} \mathrm{P}$. In some meteorites a phosphor-nickel-iror occurring in needles is found. This is the so-called rhabdite of Rose. Whether it is identical or not with schreibersite has not yet been decided, owing to the difficulty of obtaining pure material. A non-magnetic residue, consisting chiefly of transparent grains, the authors find is common in greater or less amount to most meteoric irons. In such residues a great variety of minerals have been identified with more or less certainty, such as diamond, cliftonite (a graphitic pseudomorph after diamond) quartz, tridymite, chromite, cordierite, garnet, corundum, pyroxenes both rhombic and monoclinic, \&c.

The aim of the authors in the present investigation was to answer the following questions:- How widely distributed is cohenite? Are schreibersite and rhabdite definite compounds? Has kamacite a constant composition? Has tænite always the same physical and chemical properties? What is the composition of the jagged fragments so generally left undissolved after treatment of meteoric irons with dilute hydrochloric acid? How widely distributed are the transparent grains, as well as the diamond, cliftonite, \&c. ?

Unfortunately, owing to the fact that the present joint inves tigation had to be brought to a somewhat premature conclusion, a definite answer to all of these questions could not be given We may, however, expect soon to hear more on the points stil left undecided, as the promise is made that the gaps in the present investigation shall be filled up as soon as possible.

G. T. P.

NO. I I 5 I, VOL. 45 ] 